\title{
O MODELO DE BROHM E A ORGANIZAÇÃO DO BASQUETEBOL MASCULINO BRASILEIRO
}

Leandro de Melo Beneli

Eduardo Fantato Rodrigues

Paulo César Montagner

\section{Resumo}

Este artigo buscará analisar a organização do basquetebol masculino brasileiro a partir das transformações ocorridas no esporte moderno. Para tanto, será apresentado, através da revisão bibliográfica, o modelo sociológico de Jean-Marie Brohm como referencial teórico para apoiar a discussão. Em seguida será contextualizada a trajetória institucional da modalidade relacionando-a ao processo do amadorismo para o profissionalismo. Por fim, este estudo trará uma reflexão sobre a sistematização do basquetebol masculino brasileiro, referenciado pelo modelo de organização capitalista do esporte de Brohm. Apesar da inserção do setor privado no financiamento do basquetebol, infere-se que a modalidade não acompanhou as novas exigências do esporte moderno- e, conseqüentemente, não conseguiu se ajustar às demandas advindas desta sistematização.

\section{Palavras-Chave:}

Organização do basquetebol; Transformações esportivas; Capitalismo.

\section{THE BROHM MODEL AND THE ORGANIZATION OF THE MALE BRAZILIAN BASKETBALL TEAM}

\begin{abstract}
This article objective is to analyze men's basketball organization, considering this transformation occurred in modern sport. For this, will be showed, through the bibliography research, the sociologic model by Jean-Marie Brohm as theoric referential in this discussion. Then will be conceptualized the institutional trajectory of the modality relating the process of amateurism to professionalism. Finally, this study reach to reflects about the Brazilian men's basketball systematization, based on the capitalism organization model for sport by Brohm. Despite of the basketball financing the private sector the modality didn't follow the new exigencies of modern sport, and consequently, it couldn't adjust for the necessities by this systematization.
\end{abstract}

\section{Key-Words:}

Basketball organization; Sportive transformation; Capitalism. 


\section{Pressupostos Teóricos Sobre o Modelo de Brohm}

O sociólogo Jean-Marie Brohm publicou sua principal obra, Sociologia Política do Esporte em 1976, época que se instaurava uma crise de valores no esporte e debatiam-se questões como: a escravidão do atleta, utilização ideológica do esporte, formação de campeões, comercialização predatória e a influência dos meios de comunicação e publicidade no cenário esportivo. Para o autor estes aspectos refletiam de duas maneiras, na adaptação do esporte (moderno) a organização capitalista industrial no contexto mundial e na utilização do esporte como aparelho ideológico do Estado. Brohm (1976, p. 33) define seu trabalho como:

um ensaio de sociologia geral do esporte, da instituição esportiva tomada tanto como um subsistema do sistema social global como por um sistema específico relativamente autônomo. Evidentemente tratamos de reagrupar em forma hierarquizada as categorias centrais do sistema esportivo, as quais permitem entender sua estrutura de funcionamento e o seu desenvolvimento histórico contraditório.

Como forma metodológica Brohm busca fundamentação teórica em Marx, tratando o esporte como uma totalidade em suas relações, não obstante devido às dificuldades e complexidades do esporte o autor opta por constituir uma rede de conceitos a partir de diversos autores para organização deste trabalho como: Lévy-Strauss, Weber, Freud e Althusser (BROHM, 1976).

Procurando estabelecer um paralelo entre a mercantilização do esporte e a lógica capitalista de organização social, Brohm define o sistema esportivo com o conceito de processo de produção esportiva que inserido no sistema capitalista, produz determinadas mercadorias como: campeões, espetáculos, recordes e competições. Por outro lado, o esporte também é visto como uma instituição social original, ou como o autor coloca, a instituição da competição física que reflete estritamente a concorrência econômica industrial.

Sobre a aparição do esporte moderno, seu funcionamento e estruturação do sistema esportivo, Proni (2002, p. 35) faz uma síntese e analisa a obra de Brohm.

A noção de produção esportiva justifica-se na medida em que o esporte, como forma abstrata da tecnologia corporal baseada no rendimento, inseriu-se organicamente nas formas lúdicas de exercícios competitivos, convertendo-as em técnicas altamente racionalizadas e eficazes. O principio de rendimento surge então como o motor do sistema esportivo, uma espécie de centro de gravidade em torno do qual se situam os demais elementos, um princípio pelo qual se guiam as mudanças estruturais. 
Uma das questões que a sociologia política do esporte necessita analisar é o motivo pela qual todas as formas sociais avançadas ou em desenvolvimento adotarem princípios similares no sistema esportivo, baseado na produção de campeões e na maximização do rendimento. A respeito desta inquietação, a principal hipótese de Brohm (1976, p. 63) é que:

O sistema esportivo em vias de mundialização é o reflexo da universalização e da extensão para todas as forma sociais do globo o modo de produção capitalista, porque as categorias mercantis correspondentes a esse modo de produção determinam as leis de funcionamento do sistema esportivo.

Brohm estabelece alguns conceitos sobre o advento do esporte moderno baseado na totalidade estruturada do sistema esportivo que se constitui progressivamente a partir de um sistema de dimensões mundiais. Este autor aponta algumas características relacionadas ao advento do esporte moderno que: nasce com a sociedade industrial e é inseparável de suas estruturas e funcionamento; evolui estruturando-se e organizando-se internamente de acordo com a evolução do capitalismo mundial; e assume forma e conteúdo que refletem essencialmente a ideologia burguesa.

Brohm (1976, p. 80-81) acredita que a essência do esporte moderno é a ideologia democrática típica de uma sociedade que necessita cultivar um ideal humanitário e, ao mesmo tempo, manter suas estruturas de classes e seus mecanismos de dominação.

Na lógica capitalista de organização o sistema esportivo constitui uma totalidade articulada de instâncias (econômica, cultural, ideológica política, etc) dominantes que se estrutura conforme um esquema piramidal no qual há uma hierarquia de poder e uma determinada escala de valores (BROHM, 1976, p. 88).

Do mesmo modo que há uma racionalidade que organiza os mercados e a concorrência capitalista, há um quadro de normas que regulam a competição esportiva. E como os princípios da sociedade capitalista mercantil determinam estruturalmente o esporte, as categorias socioeconômicas encontram correspondência nas categorias esportivas (PRONI, 2002, p. 43).

A respeito da funcionalidade da instituição esportiva Brohm coloca que as funções do esporte de hoje são múltiplas, contraditórias, complexas, evolutivas e diferentes das funções da época de seu nascimento. 
Para estudá-las o autor faz uma divisão de acordo com as seguintes categorias sociais: econômica, sociopolíticas, psicológicas e mitológicas.

Na instância econômica, Brohm (1976, p. 153) explica que à medida que a circulação e a valorização das mercadorias penetram no âmbito do sistema esportivo, inserindo-o nas malhas do sistema capitalista, o esporte converte-se num simples anexo funcional deste sistema.

Assim, à medida que as práticas esportivas se estruturam enquanto instituição integrada, o esporte moderno passa a obedecer a todas as leis que regem o sistema capitalista: acumulação, concentração e circulação de capitais (PRONI, 2002, p. 46).

Neste tópico foram abordados aspectos da obra de Jean-Marie Brohm que segundo Proni (2002, p. 57) tem como propósito.

Discutir a lógica de funcionamento do sistema esportivo, as funções que a instituição esportiva cumpre na reprodução da ordem social e política, assim como a reciprocidade entre a ideologia esportiva e os valores éticos e morais do capitalismo.

O modelo de Brohm parece útil para entender a organização do basquetebol masculino no Brasil, pois estão presentes questões ligadas ao processo de mercantilização esportiva, a busca de recursos financeiros, comercialização dos espetáculos, a maximização do rendimento e todas as transformações ocorridas no esporte moderno. Neste sentido, será apresentado aspecto histórico do basquetebol masculino brasileiro para que posteriormente seja feita uma análise desta trajetória institucional baseada no modelo de Brohm.

\section{A Trajetória Institucional do Basquetebol Masculino Brasileiro}

Inicialmente as práticas esportivas no Brasil predominantemente não possuíam organização sistematizada, sendo vistas apenas como entretenimento para os associados do clube, qual seja a elite clubística, e suas preocupações sócio-esportivas eram essencialmente amadoras (TREVISANI, 1997).

Ainda na década de 70 o esporte amador configurava-se como um projeto de trabalho sem seqüência, sem continuidade, e dificilmente os atletas de diferentes modalidades esportivas dedicavam-se diariamente aos exercícios e treinamentos, devido às preocupações com colégio, faculdade, emprego, ou ainda família. A improvisação, comum a todos os esportes amadores, contaminava os dirigentes amadores que não detinham recursos financeiros para elaborar um sistema esportivo organizado (NUZMAM, 1985). 
Esse contexto amador do basquetebol brasileiro trazia uma série de dificuldades para esta grande maioria de participantes das equipes competitivas, que eram obrigados a exercerem outras atividades para obterem condições para seu sustento (TREVISANI, 1997). Entretanto, essas dificuldades de sistematização e organização do desporto competitivo resultavam na maior facilidade de manutenção das equipes de competição pelo clube, pois as exigências de recursos financeiros para a sua estruturação eram de pequena escala, se considerarmos os valores atuais difundidos nos meios de comunicação. Não obstante, neste período já havia alguns jogadores que obtinham recursos financeiros através do basquetebol, entretanto, a atitude de grupos principais não evidenciava este mesmo objetivo na prática da modalidade.

No Brasil, com o intuito de acompanhar a tendência de elevação do nível do basquetebol mundial e, assim, de ampliar os horizontes profissionais da modalidade, os treinamentos começaram a ser realizados com maior freqüência, intensificando as exigências físicas, técnicas, táticas dos atletas praticantes do basquetebol.

A configuração do esporte amador foi substituída pela maior sistematização, elevando-se a quantidade de pessoas ligadas ao basquetebol que passaram a ter reconhecimento, principalmente financeiro, permitindo-as dedicar-se mais a esta prática. A preparação aumentou as exigências de investimentos, ficando cada vez mais difícil para o clube, instituição responsável pela introdução e fomentação da modalidade no Brasil, sustentar as equipes competitivas nas várias categorias, tendo, portanto que recorrer à busca de recursos externos que financiassem as crescentes necessidades requeridas pelo esporte, estabelecendo uma relação conhecida como patrocínio (BENELI, 2002).

A necessidade das equipes de contratarem pessoas mais capacitadas como fisioterapeuta, preparador físico, técnico, assistentes e dirigente elevaram a folha de pagamento do clube e este fato gerou maiores exigências de recursos financeiros para a manutenção desta nova estrutura que começava a organizar-se, resultando em modificações nas relações entre as equipes e os seus colaboradores.

Há uma dificuldade literária a respeito do financiamento e da sistematização do esporte no Brasil, porém serão apresentados alguns modelos de financiamento esportivo utilizado em outros países. Sobre a sistematização do esporte competitivo mundial e sua importância, Tubino (1997, p. 21) explica o surgimento das escolas esportivas: 
A partir da utilização do esporte como mecanismo político, principalmente após a Segunda Guerra Mundial no inicio da "Guerra Fria", o Estado se apropria do esporte em muitos países e neste momento surgem quatro escolas esportivas bem definidas: a escola saxônica, a escola socialista, a escola européia-ocidental e a escola asiática. A escola saxônica, também chamada de escola do liberalismo absoluto, tinha como base a Universidade. A escola socialista, também conhecida como escola do dirigismo absoluto, tinha no estado o organismo central de todas ações. A escola européia-ocidental, um misto das duas primeiras, justamente pelas incoerências internas entre os países componentes, sempre apresentou resultados aquém de suas possibilidades. Finalmente, a escola asiática, precursora do paradigma do esporte como negócio, tinha na indústria a sua base principal, mas delimitava-se pelas práticas esportivas inseridas nas suas culturas, o que de alguma forma explica o pequeno número de modalidades vitoriosas nas disputas internacionais.

Havia um novo desafio para os dirigentes do basquetebol brasileiro na década de 80: conseguir implantar um sistema de desenvolvimento do esporte que viabilizasse financeiramente a modalidade em um curto período frente à necessidade de manutenção de equipes esportivas representativas em condições de resultados internacionais.

Em 1981, foi deliberado o fim da proibição de empresas patrocinarem clubes ou entidades esportivas e exibirem em seus uniformes, como forma de propaganda, as marcas de seus patrocinadores. Dessa maneira, ampliaram-se as Associações Desportivas Classistas, que garantiam salários e a permanência dos atletas no país, além, obviamente de possibilitar melhores estruturas e disponibilidade para o treinamento. Esse processo culminou com a participação dessas equipes em competições destinadas ao Desporto Comunitário (MARCHI JR., 2001).

Nesse contexto, foram esboçados indícios de modernização e profissionalização do esporte amador, viabilizado na interface com a iniciativa privada. A revista Veja discutia o assunto no início dos anos 80 e mostrava que "as eventuais ajudas de custo fornecidas pelos clubes foram superadas e deram lugar aos salários advindos das empresas" (AMADORISMO..., 1983, p. 52-53).

Importante destacar que se referir à profissionalização neste momento significava reportar a uma estrutura na qual atleta de basquetebol não era uma profissão regulamentada por lei. Os mesmos eram empregados a partir de contratos de prestação de serviços para autônomos ou acordos firmados de prefeituras, sob a legislação da CLT, ou ainda em sua maioria, através de acordos verbais.

Dessa forma, vê-se a necessidade do esporte se adaptar a essa nova situação, pois apesar do esporte depender das contribuições destas empresas enquanto patrocinadoras à medida que caminhava para o 
profissionalismo, este também possuía grande importância para as empresas como meio de comunicação e propaganda.

Assim, o esporte passa a ser visto não mais como uma alternativa de lazer ou como um fenômeno social, mas como uma visão de mercado, considerando como um produto a ser vendido. Isso para atrair o interesse do público e de patrocinadores. Nesta época, o marketing esportivo que em alguns casos era praticado de forma bem simples, apenas através do comércio de espaços para a publicidade, cada vez mais vinha perdendo seu espaço para um planejamento rigoroso que se baseia nas técnicas de marketing tradicional, adaptando-se a realidade do esporte (TREVISANI, 1997, p. 18 ).

Percebe-se que diante do contexto capitalista na qual o país estava inserido, o clube não conseguia sustentar essas modalidades competitivas sem ajuda de patrocinadores. Por um lado havia a necessidade de capital nas equipes para a sua manutenção, por outro, as empresas vislumbravam um grande retorno através do marketing esportivo.

Entretanto, muitas equipes possuíam predominantemente características amadoras, e na maioria das vezes, não detinham no seu quadro funcional, pessoas capacitadas para negociar valores de patrocínio com as empresas que já estavam bem mais organizadas e preparadas para acordos com as equipes. Muitos clubes conseguiram patrocínio, porém as empresas invariavelmente levavam vantagens sobre os clubes, pois este último na ânsia de conseguir um financiamento rapidamente estabelecia algumas relações que acabaram por desvalorizar o "produto basquetebol".

Apesar da entrada das empresas patrocinadoras do basquetebol, Tubino (1988, p. 127) criticava a organização do esporte brasileiro no final dos anos 80 e mostrava:

O Esporte-performance não é assunto do Estado nem, tampouco, negócio privado. A intervenção do Estado, como poder regulamentador, é ineficiente, burocrática e paralisante. E como investidor, suas aplicações têm sido insuficientes e mal orientadas. Dessa forma, sem investir o suficiente, o Estado regulamenta o bastante para inibir a iniciativa privada. Como os clubes são, por definição estatutária e legal, entidades sem fins lucrativos, a organização, em bases capitalistas, do nosso esporte rendimento, padece de instituições privadas capacitadas. O resultado é este hibridismo asfixiante em que se estíola o esporte nacional a provocar duas sortes de demandas contraditórias: de um lado, o apelo por mais recursos públicos para o esporte de competição; de outro, o pleito por menor interferência do Estado como poder regulamentador.

Mesmo com a liberação da divulgação dos patrocinadores nos uniformes das equipes em 1983, a efetiva entrada das empresas no esporte através do marketing esportivo aconteceu apenas no final da década de 80 (PRONI, 2000).

Os estudos da FGV (KASZNAR, 1999) indicavam a defasagem do modelo desportivo brasileiro e suas diferentes formas de organização e financiamento. De acordo com este estudo, enxergava-se, de forma 
limitada, o lado empresarial e de negócios, gerador de grandes vendas e bilheterias milionárias ou de ganhos em propaganda que o esporte poderia gerar, discutindo a sua importância para questões econômicas relevantes como o PIB e a geração de empregos. Em função destes fatos, o modelo brasileiro defasou-se. Arraigou-se num conceito talvez oportuno antes dos anos 70, mas que é equivocado para o competitivo momento atual.

Em 1990 criou-se o Campeonato Nacional de Basquetebol e aumentou-se a quantidade de equipes patrocinadas por empresas. Proni (1998, p. 164) expõe sobre a entrada das empresas no esporte de rendimento:

Olhando pela ótica do esporte, essa sobreposição implicou, de um lado, privilegiar a satisfação do consumidor e, de outro, fomentar a iniciativa privada e diminuir o patrocínio público ao esporteespetáculo. E isso contribuiu para que se começasse a atribuir ao marketing esportivo um papel dominante no esporte brasileiro.

Neste sentido, a modalidade se inseria no mercado como um produto, e quanto mais aproximava do profissionalismo, surgiam novas necessidades para o seu desenvolvimento e a principal seria ligada ao financiamento dessa modalidade, porém o esporte também se torna um instrumento mais poderoso de propaganda.

Com base nas características da modalidade e em pesquisas publicitária, o basquetebol assim como o voleibol e o futebol eram modalidades adequadas para a veiculação de anúncios e ofertas de produtos e marcas. Essas informações foram absorvidas por empresários atentos aos movimentos da publicidade e do mercado. Também alguns dirigentes esportivos, embora timidamente, acenaram positivamente para a tendência, direcionando esforços na busca de recrutar empresas para patrocinar seus clubes, suas equipes e seus campeonatos (PINHEIRO, 1995).

Quanto às formas iniciais de intervenção das empresas no processo de profissionalização do esporte amador, Pinheiro (1995) destaca que existiram duas modalidades de atuação. Uma, onde a formação das equipes era fruto do apoio integral de determinada empresa, e outra, que apresentava apoio financeiro de determinada empresa a um determinado clube esportivo tradicional.

Esse processo de patrocínio das empresas ao esporte amador, em um curto espaço de tempo, trouxe aos investidores um considerável retorno publicitário, com suas marcas sendo veiculadas fartamente nos jornais, revistas e televisão.Também os atletas sentiram-se beneficiados com essa iniciativa, pois os 
treinamentos noturnos, após a jornada laborial diária, e a escassez ou obsolência do material para a prática esportiva cederam espaço para a viabilização da nova estrutura esportiva. Nelas estavam previstas as dedicações exclusivas ao treinamento, a remuneração compatível com a prestação desses serviços à empresa e, em determinados casos, assistência médica, odontológica e nutricional (FONSECA, 1984).

\section{Reflexões Acerca do Basquetebol Masculino Brasileiro}

A partir da introdução teórica do modelo de organização capitalista do esporte de Brohm, e da contextualização do basquetebol masculino brasileiro, este tópico buscará analisar e refletir sobre a sistematização da modalidade no Brasil.

Para discutir a temática primeiramente existe a necessidade de definir os conceitos de amadorismo e profissionalismo. Segundo o dicionário da língua portuguesa (FERREIRA, 2004, p. 112), amador é aquele "que se dedica à arte ou ofício por prazer, não por profissão", e este ainda define amadorismo como "condição de amador, de não profissional".

Estudos da Fundação Getúlio Vargas (KASZNAR, 1999) apontam que o esporte amador possui como característica maior o ato voluntário de exercitar uma atividade física repetidamente, da qual em tempo de lazer extrai-se a satisfação e o conforto da melhoria do bem-estar físico.

Profissional, segundo Ferreira (2004, p. 1644), é relativo à profissão compreendida como "atividade ou ocupação especializada, da qual se podem tirar os meios de subsistência". Pode-se perceber a partir desta definição que a profissionalização esportiva está amplamente vinculada à entrada de recursos financeiros para a estruturação da modalidade. Segundo Brohm e a lógica capitalista-burguesa de organização do sistema esportivo no esporte profissional há a predominância na escala de valores e na hierarquia de poder da instância econômica.

A partir dos modelos de financiamento esportivo apresentado no tópico anterior, pode ser elaborada uma breve análise sobre a organização do esporte brasileiro. A escola socialista, que o Estado controlava o esporte e os atletas eram funcionários públicos, militares ou universitários, seria difícil de ser instalada em nosso país, dada a sistematização política capitalista a qual estávamos e estamos inseridos. A escola saxônica, que proíbe a remuneração dos atletas amadores, porém recebem moradia, alimentação, cuidados médicos e ainda a oportunidade de estudar de graça, também teria dificuldades devido às diferenças econômicas e sociais entre estes países, bem como a enorme disparidade organizacional entre 
as instituições de ensino, como as Universidades e Escolas que formam a base esportiva Anglo-Saxônica. A escola asiática, apesar de ter preconizado o esporte financiado por empresas, e conforme mencionado por Tubino (1997), precursora do esporte como negócio, limitava o seu sucesso apenas as práticas esportivas inseridas em sua própria cultura e com uma realidade de ação distante do projeto brasileiro.

Proni (2000) indica a influência do modelo europeu na organização esportiva brasileira. É possível identificar a proximidade do modelo brasileiro com a escola européia-ocidental por vários motivos: característica clubística, pela participação do Estado, mais recentemente pela inserção de empresas privadas no esporte.

Brohm analisa o sistema esportivo como "processo de produção esportiva" na qual tem a necessidade de produzir certas mercadorias. Através desta relação, o clube esportivo se posicionaria como a empresa, ou como o autor qualifica, a célula básica do tecido esportivo, que inserido no sistema capitalista com suas leis inerentes seria representado a partir da sua taxa de produtividade. No entanto a célula básica no basquetebol brasileiro é composta por uma combinação, com uma disputa entre estruturas distintas, tendo clubes desempenhando sua posição enquanto empresa, empresas intervindo diretamente, equipes representando órgãos públicos, e ainda clubes sendo utilizados apenas como suporte jurídico para empresas, ou seja como um meio de produção da empresa. Assim com diferentes interesses desenvolvemse a valorização econômica e as transformações na característica clubística do país, apontadas adiante.

As transformações ocorridas no esporte moderno devido, sobretudo, pela valorização nas instâncias ideológica e econômica geraram demandas na organização do sistema esportivo e conseqüentemente, segundo Brohm (1976), na produção esportiva. Através desta constatação, percebe-se que a maximização do rendimento esportivo surge como principal fator para o desenvolvimento do esporte a partir da busca da racionalização do treinamento e, por conseguinte, na produção de mercadorias como: campeões, títulos, espetáculos, entre outros.

Neste sentido, surgiu a necessidade de mudanças na estrutura do basquetebol masculino com o aumento do número de treinos, intensificação das exigências físicas, profissionais qualificados, atletas com dedicação integral. Entretanto, estas transformações aumentaram também a demanda financeira dos clubes, que muitas vezes não possuíam recursos financeiros suficientes para a manutenção das equipes, diminuindo assim a sua taxa de produtividade. 
À medida que a modalidade se organizava, aumentava-se a exigência de recursos financeiros para a manutenção das equipes devido as crescentes necessidades com preparação física, salários de jogadores e da comissão técnica, que já se dedicavam de forma integral a modalidade.

O sistema esportivo analisado como instância social e inserido no contexto capitalista funciona de acordo com as normas e as exigências do mercado ou da competição esportiva e se desenvolve a partir da necessidade de superar a concorrência ou uma equipe adversária, respeitando assim a lógica do sistema capitalista. Observar-se que esta necessidade gradual e crescente de recursos financeiros está na transformação ou potencialização da prática esportiva, como descreveu Umberto Eco (apud MOLINA NETO, 1992, p. 358):

Inicialmente amadora e lúdica, ela se transforma em espetáculo de massa. Ação esta determinada pela lógica capitalista que transforma todas as manifestações tipicamente humanas em mercadorias e produtos de consumo. Assim, desde cedo, temos a profissionalização dos atletas e suas performances consideradas como objetos comercializáveis. Como é o caso do basquetebol profissional americano, onde Michael Jordan recebeu, para renovar seu contrato anual com a sua equipe, 5 milhões de dólares. A base de calculo foi 2 mil dólares por cada um de seus 2580 pontos na temporada.

Essa conjuntura capitalista a qual Umberto Eco se refere propiciou mudanças na organização e administração do basquetebol brasileiro. Os clubes necessitavam de dinheiro para a contratação de uma boa equipe e os patrocinadores vislumbravam um grande foco de propaganda no esporte, à medida que o marketing esportivo evoluía.

Analisando o cenário do basquetebol masculino brasileiro, se por um lado estas transformações do esporte moderno proporcionaram o aumento das preocupações de inserção neste campo e elevou o grau de estruturação das equipes, por outro lado, alguns clubes que possuíam preocupações apenas com os seus sócios optaram por abandonar esta estrutura, que gerava altos custos para disputa dos campeonatos e para manutenção das equipes, e se organizaram de forma diferente com ênfase no seu quadro de associados. Este fato pode ser observado quando clubes com grande tradição no basquetebol masculino brasileiro como Sírio e Monte Líbano, deixaram de participar dos campeonatos na categoria principal.

Para entender a trajetória institucional do basquetebol é necessária a compreensão das mudanças ou transformações do esporte moderno através da sua mercadorização. No entanto, conforme Tubino (1988), na década de 80, o Brasil ainda não havia implantado um modelo eficiente de financiamento ao "Esporteperformance", pois o Estado, ao mesmo tempo em que não possuía recursos para o completo 
financiamento das modalidades, dificultava o patrocínio de empresas no esporte amador. Segundo Proni (2000), os problemas nas negociações entre os dirigentes amadores representantes do esporte e os dirigentes profissionais representantes das empresas dificultavam a busca de recursos financeiros para as modalidades.

Na década de 90 houve uma tentativa de organização da modalidade com a criação da Liga Nacional e a inserção de forma efetiva da iniciativa privada, entretanto, surgiram conseqüências que posteriormente culminou com o fim de muitas equipes. Como exemplo pode ser citada a dependência criada entre o clube e patrocinador, e este último na maioria das vezes tinha interesse apenas no retorno que determinada equipe traria em curto prazo. A respeito deste assunto Trevisani (1997, p. 28) explica que:

Com essa necessidade crescente de investimento no esporte, chegou um momento em que o clube passou a se tornar dependente desses recursos externos, ou seja, sua ausência passou a impossibilitar os projetos com as equipes competitivas. Isso fez com que se estabelecessem relações cada vez mais ousadas na busca de investimento. Embora seja um consenso a entrada das empresas no esporte, dando condições de arcar com o crescente aumento dos custos de preparação das equipes de competição, existe a preocupação com o rumo que as relações de patrocínio estão tomando.

Este procedimento trouxe dificuldades para as equipes como a perda do vínculo com a torcida, com o clube e até mesmo com a cidade. O vínculo que se criava era com o patrocinador, ou seja, toda a responsabilidade com a equipe pertencia ao clube mais os créditos ficavam com o patrocinador por "batizar" a equipe. Todo o trabalho desenvolvido ao longo de anos para que se criasse uma tradição na modalidade, de repente era creditada a certa empresa que utilizava o esporte apenas como um meio de comunicação para a sua marca. Assim não era raro empresas e patrocinadores, preocupados com seus interesses comerciais, deslocarem-se para outras praças, no caso, outras cidades.

Quando Brohm discute a noção de produção esportiva, tendo o rendimento, como motor do sistema esportivo, determinante para influenciar na estrutura toda, ele gera expectativas tanto no campo econômico como no campo pratico, isto é, o desempenho técnico e performático é essencial para o rendimento capitalista. Observando essas constantes mudanças de patrocinadores em relação as equipes e cidades nota-se que a ênfase é muito maior no campo capitalista, as vezes deixando o desempenho pratico em segundo plano, sendo que esse deveria ser um parte decisiva para um retorno produtivo a longo prazo 
O quadro 1 demonstra a inconstância das equipes participantes do campeonato paulista de basquetebol durante dez anos, nos anos de 1991 a 2001. Apesar de muitas terem participado das quatro edições mostradas no quadro, observa-se que algumas equipes mudaram de sede como é o caso da equipe do Report/Suzano, que em 1996 mudou para a cidade de Mogi das Cruzes e 1997 mudou seu nome para Report/Valtra. O mesmo ocorre com a empresa Blue Life que patrocinava em 1991 a equipe de Rio Claro, em 1997 patrocinou a equipe do Pinheiros, e em 2001 mudou seu patrocínio para a equipe do Hebraica.

\begin{tabular}{|c|c|c|c|}
\hline 1991 & 1996 & 1997 & 2001 \\
\hline SABESP/FRANCA & FRANCA/COUGAR & MARATHON/GALLUS & FRANCA BASQUETEBOL \\
\hline E.C.PINHEIROS & E.C.PINHEIROS & BLUE LIFE/PINHEIROS & E.C.PINHEIROS \\
\hline $\begin{array}{l}\text { CESP/BLUE LIFE } \\
\end{array}$ & MIRASSOL F.C. & E.C. SÃO BENTO & HEBRAICA/BLUE LIFE \\
\hline REPORT/SUZANO & PAPEL REPORT/MOGI & REPORT/VALTRA/MOGI & VALTRA/UMC \\
\hline $\begin{array}{l}\text { S.E.PALMEIRAS } \\
\end{array}$ & S.E.PALMEIRAS & $\begin{array}{l}\text { S.E.PALMEIRAS } \\
\end{array}$ & S.E.PALMEIRAS \\
\hline C.A.PIRELLI & CORINTHIANS/AMWAY & S.C.CORINTHIANS PTA. & S.C.CORINTHIANS PTA. \\
\hline CLUBES DAS BANDEIRAS & NOSSO CLUBE LIMEIRA & BAURU/TILIBRA/COPIMAX & BAURU/TILIBRA COPIMAX \\
\hline MASTRA/NOSSO CLUBE & DHARMA YARA/FRANCA & POLTI/COC/RIB. PRETO & COC/RIBEIRÃO PRETO \\
\hline RIPASA/MONTE LÍBANO & 22 de AGOSTO & INTER WINNER & A.C.C.P/LEITOR/CASABRANCA \\
\hline TELESP CLUBE & A.A.GUARU & SING/CARREFOUR/STO ANDRÉ & EXPRESSO GUARARÁ ST. ANDRÉ \\
\hline SANTISTA TÊXTIL SÍRIO & & CLUBE DE CAMPO RIO CLARO & RIO PARDO/SADIA \\
\hline \multirow[t]{4}{*}{ IPÊ/BANESPA de JALES } & & BANCO BANDEIRANTES & T.C. CONSTRUTORA/FANDEP \\
\hline & & ASS. PERUİBE BASKETBALL & SÃO CAETANO DO SUL \\
\hline & & TRIANON CLUBE DE JACAREÍ & UNISANTA \\
\hline & & & UNIARA \\
\hline
\end{tabular}

FONTE: Federação Paulista de Basquetebol, 1991 e 2001.

Ainda a partir do quadro 1, que demonstra estas mudanças ocorridas nas equipes, podendo acarretar o rompimento dos vínculos ou mesmo da tradição da modalidade em determinada cidade, constata-se que a célula básica no basquetebol brasileiro, mencionado anteriormente, esta representada através das combinações e disputas entre clubes e empresas, e conseqüentemente, na necessidade da valorização econômica da modalidade e na superação dos interesses comerciais, no âmbito das transformações geradas pelo esporte moderno.

Outros fatores que levaram ao fim equipes também podem ser indicados, como: as estratégias das empresas em assumirem patrocínios temporários, face às condições econômicas nacionais; a concorrência por melhores atletas, que elevou os salários; e também, a "atitude predatória" das empresas no estabelecimento de metas que, após serem atingidas, descartavam as possibilidades de renovação do patrocínio (MOLINA NETO, 1992). Pode ser incluído neste contexto o despreparo dos dirigentes na leitura do mercado esportivo, o fim da competitividade nas competições regionais, a impossibilidade de 
convivência entre os clubes tradicionais e as empresas e, indissociavelmente, a concentração dos principais jogadores em poucas equipes.

\section{Considerações finais}

O modelo da lógica capitalista burguesa de Brohm pode ajudar a entender a organização esportiva do basquetebol e analisar a sua trajetória, na medida que estabelece uma discussão em torno de algumas questões que permeiam este debate. A partir destes pressupostos teóricos, percebe-se que ocorreram transformações na organização do esporte moderno, e o basquetebol também modificou suas estruturas com o intuito de acompanhar estas necessidades impostas pelo sistema de produção capitalista. $\mathrm{Na}$ medida que a iniciativa privada adentrou no financiamento do basquetebol, a modalidade conseguiu um significativo desenvolvimento na sua estrutura e organização. Não obstante, esta entrada de recursos financeiros através do setor privado e, sobretudo, pela desqualificação dos agentes responsáveis pela modalidade, trouxe conseqüências como o afastamento de equipes do cenário nacional.

Este artigo buscou analisar e refletir sobre a organização do basquetebol masculino brasileiro, e instigar para que outros estudos possam se aprofundar mais nesta temática, ou até mesmo comparar com outros modelos de organização esportiva. Entretanto, apesar de apresentar algumas modificações estruturais, a modalidade passa por certas dificuldades, pois não acompanhou as novas exigências ocorridas no esporte moderno, e conseqüentemente, não conseguiu se ajustar às demandas advindas desta sistematização esportiva. O basquetebol masculino brasileiro nos últimos anos vem perdendo espaço no âmbito nacional, especialmente para outras modalidades que conseguiram se organizar como o voleibol, e no cenário internacional, a seleção também não tem obtido sucesso nos campeonatos mundiais e nos jogos olímpicos. 


\section{Referências}

AMADORISMO em três versões. Veja, São Paulo, p. 52-54, 30 mar. 1983.

BENELI, L. M. Organização do Basquetebol Masculino Brasileiro: Reflexões sobre a trajetória institucional da modalidade a partir dos anos 70. Campinas, 2002, 81f. Monografia (Graduação) Faculdade de Educação Física, Universidade Estadual de Campinas, Campinas, 2002.

BROHM, J. M. Sociologia Politica del Deporte. Ciudad del México: Fondo de Cultura Economica, 1976.

FERREIRA, A. B. H. Aurélio: o dicionário da Língua Portuguesa. Curitiba: Posigraf, 2004.

FONSECA, D. Uma nova força nas quadras. Placar, Rio de Janeiro, p. 56-58, 28 set. 1984.

KASZNAR, I. K. O Esporte como Indústria: Solução para Criação de Riqueza e Emprego. São Paulo: Fundação Getúlio Vargas, 1999.

MARCHI JR., W. "Sacando" o voleibol: do amadorismo à espetacularização da modalidade no Brasil (1970 - 2000)., 2001. Tese (Doutorado) - Faculdade de Educação Física - Universidade Estadual de Campinas, Campinas, 2001

MOLINA NETO, V. Marketing Esportivo. Revista Brasileira de Ciências do Esporte, Maringá, n. 3, mai., 1992.

NUZMAN, C. A. Carlos Nuzman, o pai da matéria. Saque, São Paulo, n. 1, 1985.

PINHEIRO, A. B. L. F. O marketing no voleibol brasileiro no período de 1980 a 1994., 1995. Dissertação (Mestrado) - Escola de Educação Física e Desporto - Universidade Estadual do Rio de Janeiro, Rio de Janeiro, 1995.

PRONI, M. W. Esporte-espetáculo e futebol-empresa. Campinas, 1998. Tese (Doutorado) - Faculdade de Educação Física - Universidade Estadual de Campinas, Campinas, 1998.

PRONI, M. W. A metamorfose do futebol. Campinas, SP: UNICAMP/IE, 2000.

PRONI, M. W. Brohm e a organização capitalista do esporte. In: Esporte: história e sociedade. Campinas: Autores Associados, 2002.

TREVISANI, G. T. Basquetebol x Patrocinador: discutindo uma relação. Campinas, 1997, 65f. Monografia (Graduação) - Faculdade de Educação Física - Universidade Estadual de Campinas, Campinas, 1997.

TUBINO, M. J. G. In: Esporte \& Jornalismo. São Paulo, SP: CEPEUSP, 1997.

TUBINO, M. J. G. Repensando o Esporte Brasileiro. São Paulo: IBRASA, 1988. 


\section{Leandro de Melo Beneli}

Faculdade de Educação Física/UNICAMP

\section{Eduardo Fantato Rodrigues}

Faculdade de Educação Física/UNICAMP

\section{Paulo César Montagner}

Faculdade de Educação Física/UNICAMP 